\title{
THE QEDUSEN PROJECT; IMPROVING SENIORS'QUALITY OF LIFE THROUGH TO EDUCATION
}

\author{
Pilar Escuder-Mollon \\ Senior Citizens' University, \\ Universitat Jaume I, Spain
}

\begin{abstract}
Learning in later life (citizens over 65 or retired) is becoming common. The motivation and interests of the senior citizens to keep learning are mainly personal, they are not job related needs or labour market qualification requirements. These personal aims can be seen from the quality of life (QoL) perspective, where education increases well-being, integration and participation of the elderly in the present society. Institutions dealing with senior learners then face the challenge to provide a socio-educational intervention to senior learners, which has a requirements, needs and motivation different from other adults, and that specific pedagogy, courses and staff qualifications must be considered. From this need the project QEduSen (supported by the Lifelong Learning Programme of the European Commission) produced a guide and a evaluation toolkit
\end{abstract}

Keywords: senior education, elderly, quality of life

\section{Background}

Ageing is one of the greatest social and economic challenges of the 21 st century for the European societies. It will affect all the Member States and it will cut across nearly all the EU policy domains. By 2025 more than $20 \%$ of Europeans will be 65 or over, with a particularly rapid increase in the number of citizens over 80s (Eurostat).

It is a fact that institutions that teach to seniors ( +65 years old or retired) face the issue to offer courses to a target not aimed to get a degree or to improve at job, therefore they have to apply different methodologies and also create courses, activities and materials specially designed. In broader aspect, their main aim is to increase their well-being and Quality of Life (QoL). In this context, teaching becomes a socio-educational activity, where more formal, non-formal and informal activities mix. The knowledge acquired is important, but there are skills and attitudes that should not be forgotten and other aims as, socialization, integration, adaptation to society, active citizenship, etc.

Existing research define the QoL both as an objective and subjective perception of the individual (Rapley 2003). There are also parameters to help to evaluate it and therefore to take action to increase the QoL of one individual (Cummings 1997, Schalock 2000, WHO 1997). The levels of QoL may decrease because of several kinds of risks (e.g. loneliness, isolation...) and may increase through some other activities promoting integration or communication. Education can be used to minimize the risks and maximize the QoL. The promotion and increase of QoL in senior citizens is greatly positive as it will make not only happier 
seniors, but also more active, productive, participative, healthier and that require less social services and increase their valorisation in society.

\section{The importance of educational}

There are public institutions, non governmental organisations, associations and also laws and regulations that fight against poverty, exclusion, discrimination and other social aspects that crate suffering and unfair living conditions. From global to local (families, friends, individual) it is a good cause to take actions to have a better quality of life.

From the global-local perspective, it is possible to act on individual QoL through education. Learning has many stages in life, while children have to learn the most basic knowledge and social skills, training in adolescents and adults is more oriented to professional skills and competitiveness. On the elderly or retired people, there is not any aim to promote at work, their motivation are purely personal. Most commons reason they want to learn are mainly to know about some subject that they have curiosity, they want to know more about the present society and history, understand it, and be up to date, they do not want to get excluded and they want to be active and creative. On the other hand, institutions offer this kind of educational activities because they know that they are beneficial for seniors citizens; it make them more skilled to face the present society challenges, more active and participative. Those concepts are very related with the purpose of increase the seniors' QoL as we will see in next chapters.

The design of any educational intervention aimed to increase the QoL of learners is not a target that can be reached in short-term through a subject or any other kind of activity. This very broad aim, requires a carefully design of the whole teaching-learning process which involve non only the content, but how it is been thought, how learners interact, the environment, an a lot more other aspects that you will be able to discover through this guide.

The seniors' QoL can be impacted through education, but as like any other habit, skill or attitude, QoL can be learnt as the same way that tolerance, friendship or to face up challenges conveniently.

\section{The QEduSen project}

The QEduSen project "Evaluation toolkit on seniors education to improve their quality of life" is supported by the Lifelong Learning Programme of the European Commision with reference 518227-LLP-1-2011-1-ES-GRUNDTVIGGMP from October 2011 to September 2013.

You can find more information about this project in http://www.edusenior.eu and about the LifeLong Learning Programme of the European Commision at 
http://ec.europa.eu/education/lifelong-learning-programme. On Figure 1 it can be seen a general overview of the project.

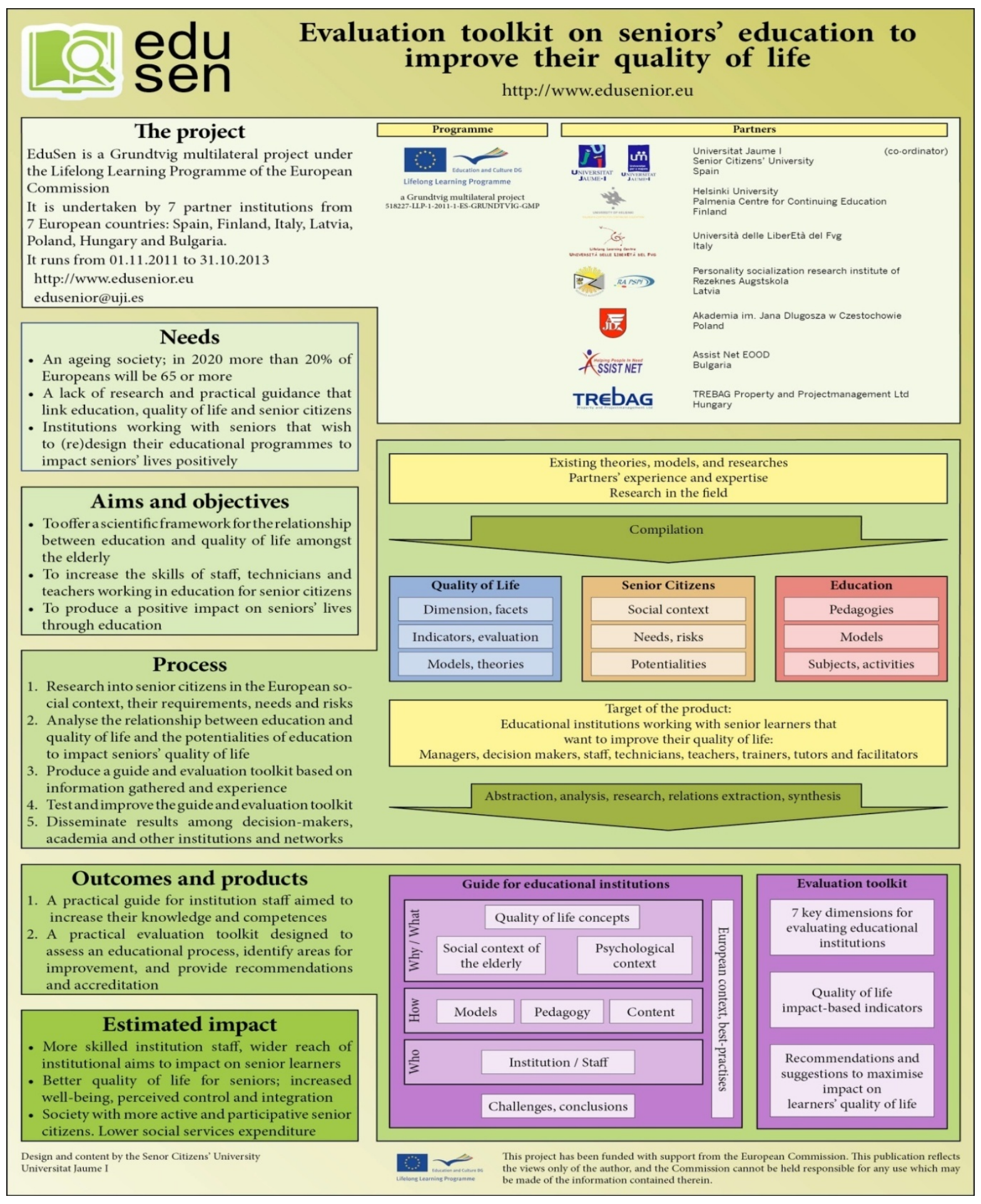

Fig. 1 General overview of the QEduSen project

The first product is a guide, with 7 chapters that introduce 7 topics: Quality of life, The elderly, Society, Models, Pedagogy, Content, Staff/Trainers. 
In each chapter, a theoretical background is provided to introduce the basic concepts about each topic. In the same chapter, a more practical sections follows with practical experiences that can be useful for any inexperienced institution, getting by this way ideas and practises that can be implemented.

Thanks to application of this guide by any inexperienced institution focused to adults or adults education association is that those institution can implement an education program to increase the QoL of senior learners.

The second product of the guide is an evaluation toolkit, that is a tool that can be applied in any institution with the aim to evaluate the effectiveness of the educational action impacting the seniors' QoL.

This toolkit can be used as a way of accreditation for any institution, getting by this way a value on which it can be measured, but also as a way to get feedback to improve the weaknesses and getting advices. The toolkit is a very practical tool, as it provides for each indicator a justification and recommendations.

\section{Conclusion}

A person's QoL has objective and subjective factors. When basic requirements for living are covered and there are not severe physical or psychological challenges, then it becomes more subjective. It is more related to the personal believes, attitudes, our relation with our environment and our perceived control. All those aspects can be modified thanks to education, but that is not a easy task, neither it can be achieved in short time, but in a long time.

The benefits of having a good QoL is not only beneficial for the individual, but also for the society, that can benefit from a senior more active and participative, also generating less expenses to the society, lowering the chances for depression or illness.

\section{Acknowledgments}

You can find more information about this project in http://www.edusenior.eu and about the LifeLong Learning Programme of the European Commission at http://ec.europa.eu/education/lifelong-learning-programme.
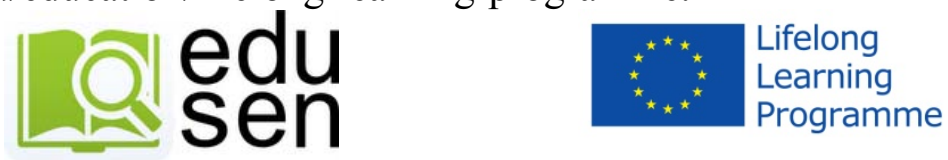

The QEduSen Project "Evaluation toolkit on seniors education to improve their quality of life" is supported by the Lifelong Learning Programme of the European Commision with reference 518227-LLP-1-2011-1-ES-GRUNDTVIG-GMP from October 2011 to September 2013

This project has been funded with support from the European Commission. This publication reflects the views only of the author, and the Commission cannot be held responsible for any use which may be made of the information contained therein. 


\section{Bibliography}

1. Cummins, R. A. (1997). Comprehensive quality of life scale: adult: manual (5th ed. (ComQol-A5).). Burwood Vic.: Deakin University School of Psychology. Retrieved from http://www.deakin.edu.au/research/acqol/instruments/comqol-scale/comqol-a5.pdf

2. Escuder-Mollon, Pilar, Esteller-Curto, R, Ochoa, L., Bardus, Massimo (2013). Impact on Senior Learners' Quality of Life through Lifelong Learning. Procedia Social and Behavioral Sciences. Inprint.

3. QEduSen (2013). Analysis of requirments. Available at http://www.edusenior.eu

4. Rapley, M. (2003). Quality of Life Research. A Critical Introduction, London: Sage

5. Schalock, R. L. (2000). Three Decades of Quality of Life. Focus on Autism and Other Developmental Disabilities, 15(2), 116-127. doi:10.1177/108835760001500207

6. WHO. (1997). WHOQOL. Measuring Quality of Life. World Health Organisation. Recuperado a partir de http://www.who.int/mental_health/media/68.pdf

\begin{tabular}{|r|l|}
\hline Pilar & Senior Citizens' University \\
Escuder-Mollon & Universitat Jaume I. \\
& Av. Vicent Sos Baynat s/n 12071 Castellón, \\
& Spain. \\
& E-mail: $\underline{\text { mollon@ } @ \text { uji.es }}$ \\
& Tel.: 964729322 \\
\hline
\end{tabular}

